\title{
Anatomical Characteristics of Hertia cheirifolia L.
}

\author{
Kaouther Majouli, ${ }^{12}$, Assia Hamdi ${ }^{3}$, Zohra Marzouk2 ${ }^{2}$, Zohra Houas ${ }^{4}$ and Abderraouf Kenani ${ }^{2}$ \\ ${ }^{1}$ Department of Biology, College of Science and Arts-Sajir, Shaqra University, Saudi Arabia \\ ${ }^{2}$ Faculty of Medicine, Laboratory LR $18 E S 40$ of "Environment, Inflammation, Signaling and Pathologies", \\ University of Monastir, Tunisia \\ ${ }^{3}$ Faculty of Pharmacy, Laboratory of Chemical, Galenic and Pharmacological Development of Drugs, \\ University of Monastir, Tunisia \\ ${ }^{4}$ Faculty of Medicine, Laboratory of Histology-Cytology and Genetics, University of Monastir, Tunisia
}

\begin{abstract}
Hertia cheirifolia L. is medicinal plant and known as a medicinal plant having several pharmaceutical and biological activities. Hence, anatomical characterization of this plant is essential. The present study reports the anatomy of $H$. cheirifolia to locate and understand the tissue structures of its leaves, stems and roots with the aim of providing further information about this medicinal plant. Cross-sections were performed and anatomical characteristics were distinguished through light microscopy observation. The results provide fundamental knowledge concerning the tissue structures in $H$. cheirifolia organs with bilateral symmetry for leaves and axial symmetry for stems and roots.
\end{abstract}

\section{Keyword}

Medicinal plant, Tissue structure, Vegetative organs

\section{Introduction}

The family of Asteraceae presents very homogeneous morphological characteristics mainly on its characteristic inflorescences "the head inflorescence". The flower head that resembles a single solitary flower is composed of ligulate flowers and/or tubular flowers [1,2]. This characteristic distinguishes members of Asteraceae from other species that bear only simple forms of flowers in their inflorescences.

Hertia is a genus taxonomically belongs to the Asteraceae family. According to the study conducted by [3], Hertia represents twelve species which of Hertia cheirifolia $\mathrm{L}$. is endemic to Tunisia.

Morphologically, $H$. cheirifolia is a sub-shrub $(20-40 \mathrm{~cm})$ with alternate leaves. The stems are succulent and the fruits are achenes with a crowned summit of pappus. The seeds are without albumen and with two voluminous cotyledons loaded with fat [4].

Previous studies have shown that $H$. cheirifolia has important chemicals and biological activities such as spasmolytic and anti-inflammatory effects [5]; acaricidal activity [6]; antibacterial activity [7]; antioxidant activity and $\alpha$-glucosidase inhibition [8].

Morphological characteristics are often used to identify species, however when the morphology is similar, anatomical characterization is essential for identification. Anatomical characters can be useful as supportive evidence in scientific tests and pharmacognosy to help identify the plant species and phytochemicals. Thus, anatomical evidence may often give additional indications as to the identity of the plant when phytochemical studies prove inconclusive. Anatomical characters of potential diagnostic value will be presented for a selection of medicinal plant.

According to literature survey, there are no reports on the anatomical study of $H$. cheirifolia, and due to its medicinal importance, the present work aims to investigate its anatomical characteristics.

\section{Materials and methods}

H. cheirifolia was collected at the flowering stage in February from Thala in Tunisia. Fresh leaves, stems and roots were separately sectioned. A voucher specimen (Hc 112) was deposited in the Laboratory of Medicinal Chemistry and Natural

*Corresponding author: Kaouther Majouli, Department of Biology, College of Science and Arts-Sajir, Shaqra University, Saudi Arabia

Accepted: December 29, 2020

Published online: December 31, 2020

Citation: Majouli K, Hamdi A, Marzouk Z, et al. (2020) Anatomical Characteristics of Hertia cheirifolia L.. J Bot Res 3(1):119-122 
Products at the Faculty of Science of Monastir, Tunisia.

To locate the structures of the species $H$. cheirifolia, many fragments of the stems, leaves and root were fixed in $70 \%$ ethanol solution [9]. Histological sections are carried out at the Laboratory of Plant Biology of the Faculty of Pharmacy of Monastir and photographed at the Laboratory of Histology at the Faculty of Medicine of Monastir.

Cross-sections were performed using a razor blade for all of the samples. The sections should be as thin as possible and the cutting plane should be perpendicular to the major axis of the organ. The approximate thickness of the sections was 15 microns. Then they are immersed in different baths; bath 1 containing sodium hypochlorite, for $15 \mathrm{~min}$, in order to clear the cells of their contents. In bath 2, the cuts are rinsed with distilled water. Bath 3 containing the $5 \%$ acetic acid, for 5 min, for a good fixation of the stain. Bath 4 containing a double stain: carmino-green (acetic carmine and iodine green), for $15 \mathrm{~min}$. The acetic carmine stains cellulosic walls and the iodine green stains lignified walls. The sections are rinsed with distilled water and observed using a Leica DM750 light microscope equipped with a Leica ICC50 camera (Germany).

\section{Results and Discussion}

\section{Anatomical structure of the leaves}

The observation of a transverse section of the $\mathrm{H}$. cheirifolia leaf shows bilateral symmetry. We distinguish from the outside to the inside; epidermal cells (Figure 1) which are protective cells against physical aggressions and pathogens. They are thick-walled and tightly packed in a single layer. This thickening corresponds to a deposit of a waxy substance secreted by the epidermis called cuticle. Trichomes are absent. Stomata in the epidermis permit gas exchange between the plant and the atmosphere. Collenchyma occurs in a peripheral position and it is distinguished by having uniformly thickened walls (Figure 1). The cells of this annular collenchyma are supporting cells which are located under the epidermis, with walls provided with elastic cellulosic thickening. This type of collenchyma is located in many stems and petioles of dicots [10].

The secretory canal (Figure 2) is formed by a cavity surrounded by two cellular bases which the internal is secreting and the external plays a protective role. In the literature, there are descriptions of secretory canals of Asteraceae species [11,12]. However Mabel, et al. [13], and Ekeke and Mensah [14] did not report the presence of secretory structures in the leaf of the plant. The essential oil present in $\mathrm{H}$. cheirifolia can be found in secretory canals.

The Figure 3 show cells of palisade parenchyma and spongy parenchyma. The palisade parenchyma cells are elongated and oriented perpendicular to the leaf surface. It is at the level of this parenchyma that the photosynthesis takes place. While, spongy parenchyma cells are composed of irregularly shaped cells and large intercellular spaces.

On the ventral side, the xylem allowing the transport of the raw sap (water and mineral salts); it consists of conduc-

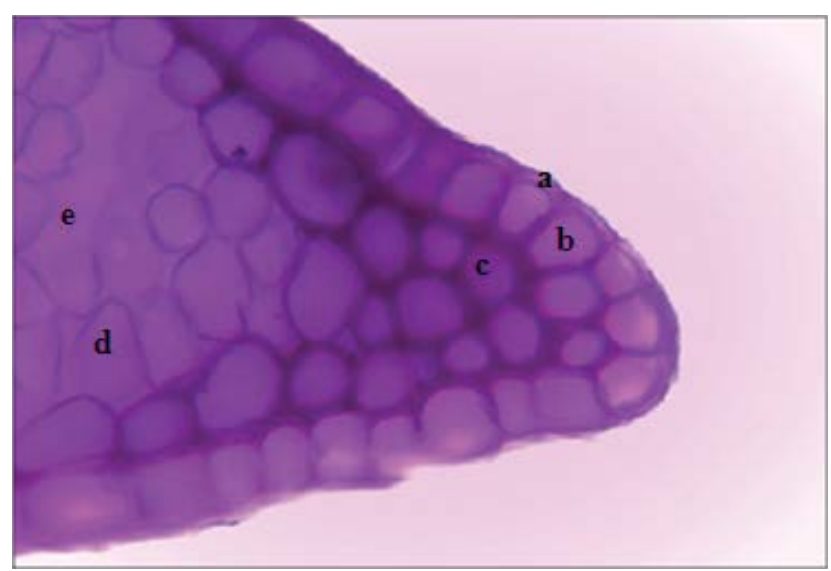

Figure 1: Anatomical organization of transverse section of a sector from the Hertia cheirifolia leaf $(40 x)$. a) Cuticle; b) Epidermal cell; c) Collenchyma cell with annular thickening; d) Parenchyma cell; e) Gap.

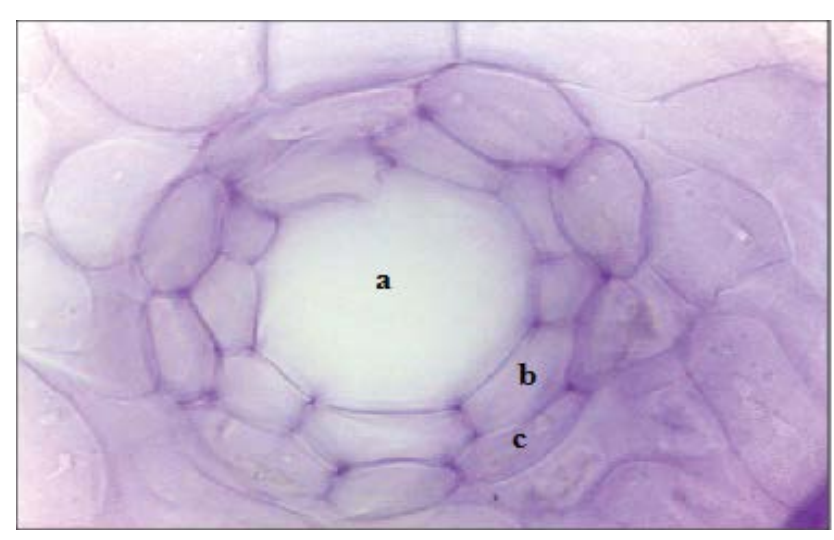

Figure 2: Organization of transverse section of a secreting channel from the $H$. cheirifolia leaf $(100 x)$. a) Cavity of canal; b) Secreting cell of canal; c) Protective cell of canal.

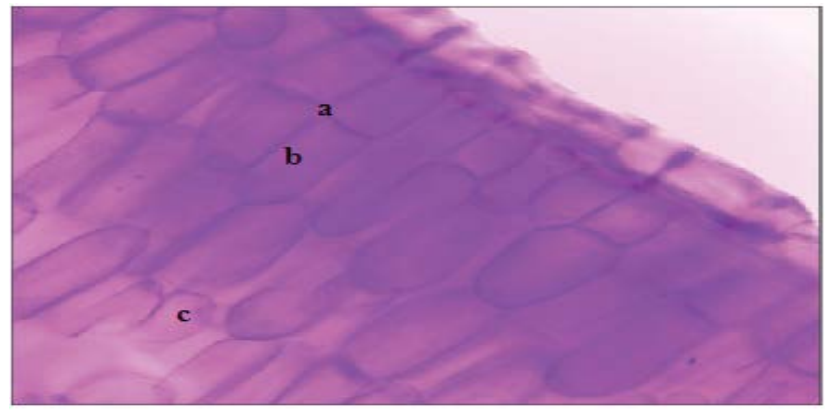

Figure 3: Organization of transverse section of palisade parenchyma from the $H$. cheirifolia leaf (40x). A) Intercellular spaces; b) Palisade parenchyma; c) Spongy parenchyma.

tive vessels (Figure 4). But, on the dorsal side, the sieve tubes ensure the circulation of the elaborated sap (water, saccharose, amino acids, hormones and certain ions). The companion cells provide an energetic role and the parenchymatous cells serve for the storage and the mobilization of the reserves (Figure 4). 


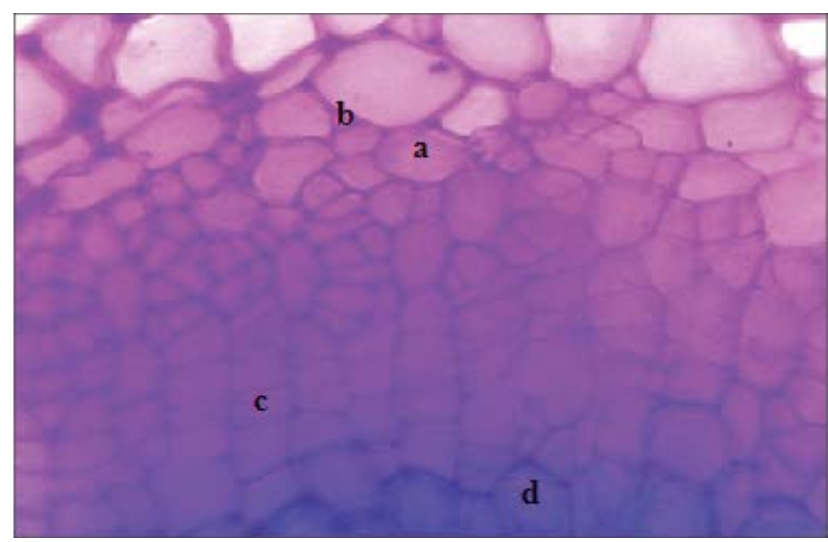

Figure 4: Organization of transverse section of the main rib from the $H$. cheirifolia leaf (40x). a) Tube riddled of phloem; b) Companion cell; d) Conductive vessel of xylem.

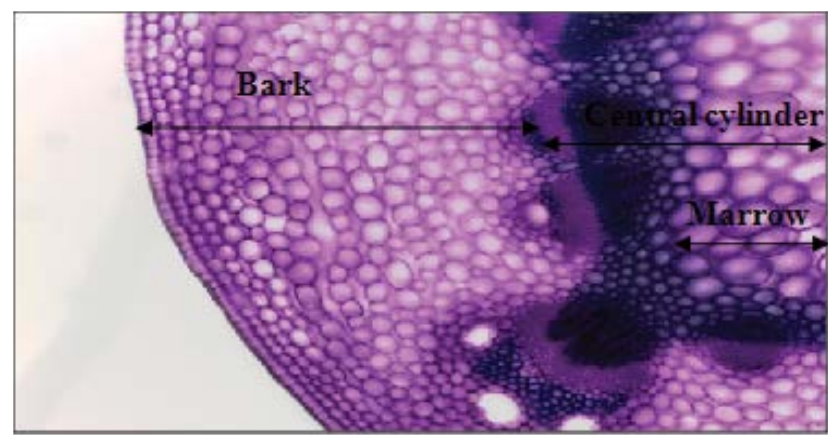

Figure 5: Organization of transverse section of a sector from the H. cheirifolia stems (10x). a) Bark; b) Central Cylinder; c) Marrow.

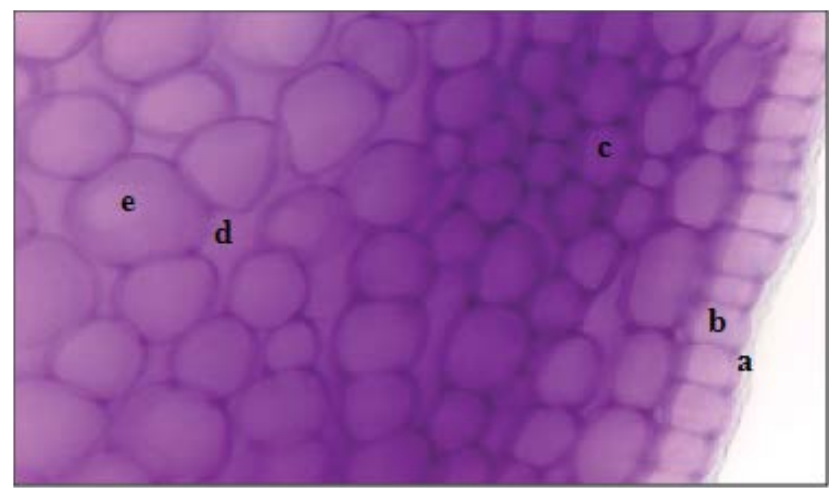

Figure 6: Anatomical organization of transverse section of a sector of the stem bark from $\mathrm{H}$. cheirifolia (40x). a) Cuticle; b) Epidermal cell; c) Collenchyma; d: Meat; e) Cortical parenchyma.

\section{Anatomical structure of the stems}

The anatomical organization of the stem of $\mathrm{H}$. cheirifolia (Figure 5) shows axial symmetry. The bark (Figure 6) is a narrow outer covering formed by a cuticle. In most cases the epidermis is slaughtered off during secondary growth. The annular collenchyma and cortical parenchyma have the same functions as those recorded in the leaf. The bark is rich in secreting pockets (Figure 7).

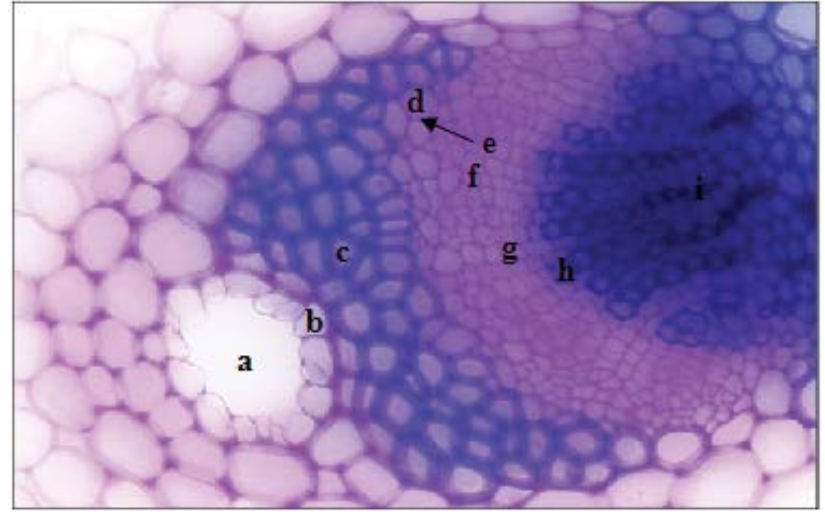

Figure 7: Anatomical organization of transverse section of a sector of the stem (central cylinder and bark) from $\mathrm{H}$. cheirifolia (40x). a) Secreting pocket; b) Secretory cell; c) Sclerenchyma of sclerotic cell type; d) Cell of screened tube; e) Cell companion; $f$ ) Parenchyma cell; g) Cambial zone; h) Conductive vessel of xylem; i) remainder of xylem.

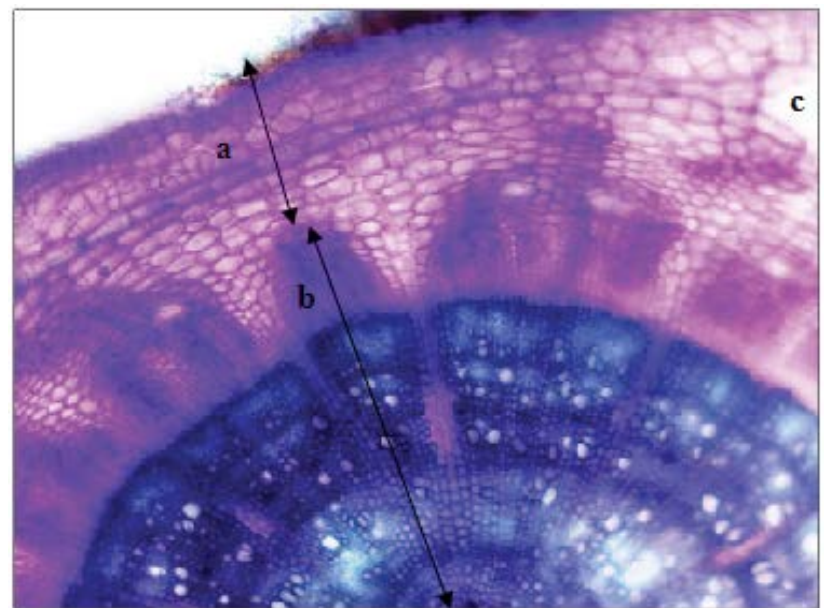

Figure 8: General organization of transverse section of a sector from $H$. cheirifolia root (10x). a) Bark; b) Central cylinder; c) Portion of a secretory pocket.

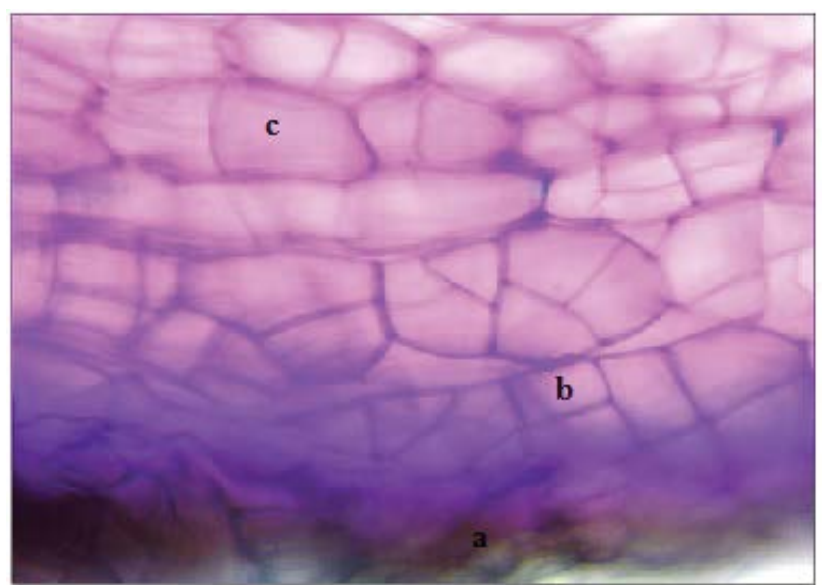

Figure 9: Organization of transverse section of a sector of the bark from $H$. cheirifolia root (40x). A) Suberin; b) Cell of phelloderm; c) Cell of cortical parenchyma. 
The vascular cylinder is more important than the bark. It contains sclerenchyma of the sclerotic cell type with thick and lignified walls (Figure 7). Xylem and phloem occur in vascular bundles. Primary xylem formed by conducting vessels with lignified walls which serve to transport the raw sap (Figure 7). Phloem formed by sieve tubes which have the role of the circulation of the sap elaborated in the opposite direction of the raw sap. A cambial zone is located between the xylem and phloem, it is formed of meristematic cells ensuring the formation of xylem and phloem allowing thickness growth. The cambium layer gives rise to phloem cells on the outside and xylem cells on the inside.

\section{Anatomical structure of the roots}

A cross-section of the $H$. cheirifolia root, stained with carmine-green, shows axial symmetry (Figure 8 ). The bark consists of lignified cells which secrete the suberin. The epidermis contains many root hairs. As the root matures, the root hairs are lost from the epidermis. A phelloderm formed by parenchymal cells is formed within the phellogen. Schizogenic secreting pockets are also observed in a cellulosic cortical parenchyma (Figure 9).

The vascular bundle (Figure 10) is formed by xylem and phloem. The xylem contains conductive vessels and lignified parenchyma. Vessels provide transport longitudinally. The phloem shows the same organization as that of the stems.

\section{Conclusion}

In conclusion, the histological sections applied to the different organs of $H$. cheirifolia show tissue structures with bilateral symmetry for leaves and axial symmetry for stems and roots. As well, the presence of the pockets and the canals secretory of the essential oils has been reported. This study is also important for further taxonomical studies in genus $\mathrm{Her}$ tia. This is the first study of its kind report on the anatomy $\mathrm{H}$. cheirifolia.

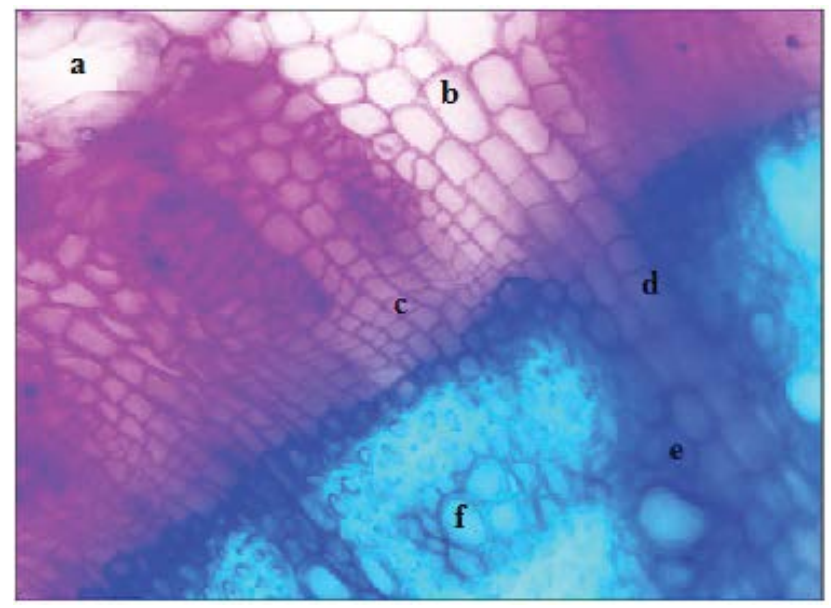

Figure 10: Organization of transverse section of a portion of xylem from $H$. cheirifolia root (40x). a) Secreting pocket; b) Cell of phloem; d) Cell of xylem; e) cell of sclerified parenchyma of xylem; f) Conductive vessel of xylem.

\section{Acknowledgement}

We are very grateful to the team of Laboratory of Transmissible Diseases and of Biologically Active Substances, MDT01, Faculty of Pharmacy and University of Monastir, Tunisia).

\section{Conflicts of Interest}

All authors declare no conflict interest.

\section{References}

1. Harris EM (1995) Inflorescence and floral ontogeny in Asteraceae: A synthesis of historical and current concepts. Botanical Review 61: 3-278.

2. Barkely TM, Brouillet L, Strother JL (2006) Asteraceae. In: Flora of North America Editorial Committee. Flora of North America, North of Mexico, Oxford University Press, New York 19: 3-69.

3. Akhgar MR, Shariatifar M, Akhgar AR, et al. (2012) Chemical composition and antibacterial activity of the leaf essential oil from Hertia Intermedia. Chem Nat Compd 48: 329-331.

4. Pottier-Alapetite G (1981) Flora of Tunisia. Angiosperms-dicotyledons gamopetales. Tunisian Scientific Publication.

5. Ammar S, Edziri H, Mahjoub MA, et al. (2009) Spasmolytic and anti-inflammatory effects of constituents from Hertia cheirifolia. Phytomedicine 16: 1156-1161.

6. Attia S, Grissa KL, Mailleux AC, et al. (2012) Acaricidal activities of Santolina africana and Hertia cheirifolia essential oils against the two-spotted spider mite (Tetranychus urticae). Pest Manag Sci 68: 1069-1076.

7. Majouli K, Besbes Hlila M, Hamdi A, et al. (2016) Antioxidant activity and $\alpha$-glucosidase inhibition by essential oils from Hertia cheirifolia (L.). Ind Crops Prod 82: 23-28.

8. Majouli K, Hamdi A, Msaada K, et al. (2017) A bioactivity guided study on the antibacterial activity of Hertia cheirifolia L. extracts. Microb Pathogen 106: 113-118.

9. Berlyn GP, Miksche JP (1976) Botanical microtechnique and cytochemistry. lowa State University, Ames.

10. Leroux $O$ (2012) Collenchyma: A versatile mechanical tissue with dynamic cell walls. Ann Bot 110: 1083-1098.

11. Millani AA, Rossatto DR, Rubin Filho CJ, et al. (2010) Growth analysis and leaf anatomy of the medicinal plant Ageratum conyzoides L. (Asteraceae) grown on different substrates. Rev Bras Plants Med 12: 127-134.

12. Bartoli A, Galati BG, Tortosa RD (2011) Anatomical studies of the secretory structures: Glandular trichomes and ducts, in Grindelia pulchella Dunal (Astereae, Asteraceae). Flora 206: 1063-1068.

13. Mabel AF, Johnson AA, Olufemi OO, et al. (2014) Foliar anatomy of some species of Asteraceae in South Western, Nigeria. Afr J Plant Sci 8: 426-440.

14. Ekeke C, Mensah SI (2015) Comparative anatomy of midrib and its significance in the taxonomy of the family Asteraceae from Nigeria. J Plant Sci 10: 200-205. 